\title{
Management of Obsessive-Compulsive Disorder
}

\author{
Phillip J. Seibell ${ }^{1 *}$ and Eric Hollander ${ }^{2,3}$
}

Addresses: ${ }^{1}$ Department of Psychiatry, Weill-Cornell Medical College/New York Presbyterian Hospital, 21 Bloomingdale Road, White Plains, NY, 10605, USA; ${ }^{2}$ Albert Einstein College of Medicine/Montefiore Medical Center, Child Psychiatry Annex, 3340 Bainbridge Avenue, Bronx, NY 10467, USA; ${ }^{3}$ Spectrum Neuroscience and Treatment Institute, 901 Fifth Avenue, New York, NY 10021, USA

*Corresponding author: Phillip J. Seibell (phs2007@med.cornell.edu)

Fl000Prime Reports 2014, 6:68 (doi:10.12703/P6-68)

All FI000Prime Reports articles are distributed under the terms of the Creative Commons Attribution-Non Commercial License (http://creativecommons.org/licenses/by-nc/3.0/legalcode), which permits non-commercial use, distribution, and reproduction in any medium, provided the original work is properly cited.

The electronic version of this article is the complete one and can be found at: http://f1000.com/prime/reports/m/6/68

\begin{abstract}
Obsessive-compulsive disorder (OCD) is a common, often debilitating disorder characterized by the presence of obsessions and compulsions. Obsessions are repetitive thoughts or images which are experienced as intrusive and unwanted; they cause marked anxiety and distress. Compulsions (also known as rituals) are repetitive behaviors or mental acts that individuals with OCD perform in an attempt to decrease their anxiety. Patients tend to hide their symptoms due to shame; the amount of time between onset of symptoms and appropriate treatment is often many years. The disorder likely results from several etiological variables; functional imaging studies have consistently shown hyperactivity in the orbitofrontal cortex, anterior cingulate, thalamus, and striatum. The mainstays of treatment include cognitive-behavioral therapy in the form of exposure and response prevention (ERP) and serotonin reuptake inhibiting medications. Several pharmacological augmentation strategies exist for treatment-resistant OCD, with addition of antipsychotics being most commonly employed. Radio and neurosurgical procedures, including gamma knife radiation and deep brain stimulation, are reserved for severe, treatment-refractory disease that has not responded to multiple treatments, and some patients may benefit from transcranial magnetic stimulation.
\end{abstract}

\section{Introduction}

OCD is an often debilitating disorder characterized by the presence of obsessions and compulsions. Obsessions are repetitive thoughts or images which are experienced as intrusive and unwanted; they cause marked anxiety and distress. Compulsions (also known as rituals) are repetitive behaviors or mental acts that individuals with OCD perform in an attempt to decrease their anxiety [1]. For example, an individual with contamination obsessions may experience great anxiety after touching a public toilet seat. In response to this anxiety, the individual may wash his or her hands repetitively in an attempt to get rid of the "contamination". A vicious cycle develops in OCD whereby every time a compulsive behavior or mental act (for example, neutralizing a "bad" thought with a "good" thought) is performed, OCD worsens, leading to an intensification of obsessions and compulsions [1]. Certain symptom categories are common in OCD. These include contamination, symmetry, ordering/counting, forbidden thoughts/images/scrupulosity, and harm. Those with contamination symptoms will experience contamination obsessions and cleaning/washing compulsions. Symptoms in the symmetry category include a need for alignment of objects. Some patients engage in ordering or counting to prevent a dreaded outcome. Patients may experience forbidden/horrific thoughts or images and attempt to neutralize them with compulsions. Scrupulosity obsessions and compulsions that are outside the typical boundaries of a particular religion are also common. Those with harm OCD experience symptoms related to harm coming to self or others; checking compulsions are common in this category (for example, in order to prevent a fire, an individual may repetitively check to see whether or not the stove has been turned off). The recently published 
Diagnostic and Statistical Manual of Mental Disorders-Fifth Edition (DSM-V) has moved OCD out of the "Anxiety Disorders" category and placed it within a new category: Obsessive-Compulsive and Related Disorders [1]. In creating this new category of disorders, hoarding, previously categorized as a subtype of OCD, is now its own disorder (hoarding disorder). We will focus here on OCD, but the reader may consult a review on the treatment of hoarding [2].

\section{Epidemiology}

OCD occurs in $1.2 \%$ of the population $[3,4]$ in the United States and similar rates are seen across cultures [5]. In childhood, males are more commonly affected; the reverse is true in adulthood $[4,5]$. The mean age of onset is 19.5 years; males tend to have an earlier age of onset than females [4]. Onset after age 35 is rare but can occur. The onset of symptoms is generally gradual. If OCD goes untreated, the course is typically chronic with waxing and waning symptoms, and remission rates are low $[6,7]$.

\section{Etiology/Pathophysiology}

OCD likely results from multiple variables. Genetic factors are implicated: Monozygotic twins are much more likely to exhibit OCD symptoms than dizygotic twins [8]. Studies of first-degree relatives have indicated that family members are at greater risk [9]. It has been argued that there is an autosomal dominant mode of transmission [9-12]. There is an association between pregnancy and the development of obsessive-compulsive symptoms: Among 59 female OCD patients, 39\% of women described onset of OCD symptoms during pregnancy [13]. Onset of symptoms after striatal lesions or head trauma has also been described [14]. As the mainstay of pharmacological treatment for OCD includes serotonin reuptake inhibiting medications, it appears clear that dysfunction within the serotonin system plays a role in pathophysiology [15]. Functional neuroimaging studies have illustrated that a hyperactive brain circuit exists in OCD; areas involved include the orbitofrontal cortex, anterior cingulate, thalamus, and striatum [16]. Evidence for dysfunction in these areas also appears to exist in children [17]. A decrease in metabolic activity in the hyperactive brain circuit has been shown to occur after administration of selective serotonin reuptake inhibitors (SSRIs) or cognitivebehavioral therapy $[18,19]$. In addition, some patients appear to develop or experience an exacerbation of OCD symptoms following beta-hemolytic streptococcal infection. It is thought that antibodies that are produced cross-react with basal ganglia proteins; this phenomenon has been named "PANDAS" (pediatric autoimmune neuropsychiatric disorders associated with streptococcal infection) [20].

\section{Diagnosis/Rating Scales}

The diagnosis of OCD is typically made using DSM-V criteria as a guide [1]. The Yale-Brown ObsessiveCompulsive Scale (Y-BOCS) is the most widely used measure of OCD symptoms. It has been demonstrated to be valid and can be used as a self-report or clinicianadministered scale; both adult and child versions exist [21]. Both versions have a symptom checklist and a severity rating scale. The symptom checklist provides clinicians with data on specific symptom types/domains that require further attention. The severity scale has 10 questions -5 about obsessions and 5 about compulsions - and the overall score is used to rate symptom severity.

\section{Treatment}

The mainstay of treatment for OCD includes cognitivebehavioral therapy in the form of ERP and medication management (most commonly with serotonin reuptake inhibitors, or SRIs). The initial treatment choice depends on illness severity. A mild to moderate severity of illness, which is indicated by a Y-BOCS score of 8 to 23, can be treated with either ERP or administration of an SRI alone [22]. However, most medication trials in OCD used only a 25\% to $35 \%$ reduction in Y-BOCS scores as a benchmark of efficacy in order to gain US Food and Drug Administration (FDA) approval. In addition, in a study that examined ERP versus drug treatment alone, ERP was found to be more effective [23]. Therefore, if it is available, ERP is generally recommended as the first-line treatment for mild to moderate symptoms. For more severe symptoms, medication management in combination with ERP is recommended. In fact, some patients with severe OCD will have difficulty engaging in ERP if they are not exhibiting a medication response beforehand.

\section{Exposure and Response Prevention}

An individual with OCD who engages in treatment with a skilled cognitive-behavioral/ERP therapist can make significant gains overall in level of functioning and quality of life. The effectiveness of ERP has been clearly demonstrated in OCD $[23,24]$. The first step in any OCD treatment includes providing psychoeducation about the illness and the ERP process. Patients are encouraged to complete a 24-hour obsession and compulsion symptom $\log$ after the Y-BOCS is administered, and these data are used in the construction of a hierarchy of symptom triggers. Symptom triggers are rated on a scale from 0 to 100, often using 10-point intervals. For example, a patient with contamination symptoms might consider touching a public doorknob less anxiety-provoking (rated a lower number) than touching a public toilet seat. Patients are then encouraged to work on doing "exposures" by moving up their hierarchies. An example of an exposure exercise 
would be holding on to a "contaminated" doorknob. The individual is encouraged to continue holding onto the doorknob until his or her anxiety decreases substantially. It is important that patients are encouraged to expose themselves to triggers during therapy sessions and that they leave sessions with well-defined ERP homework assignments. We recommend that patients engage in at least one hour of ERP each day in order to increase the odds of a successful outcome. It is important to emphasize that provoking OCD on purpose (planned exposures) is just as important as resisting the urge to engage in compulsions following an unplanned (naturalistic) exposure.

\section{Medication Management}

Five compounds have FDA approval for the treatment of OCD: clomipramine (a tricyclic antidepressant) and four SSRIs (fluoxetine, fluvoxamine, paroxetine, and sertraline). Numerous studies have assessed the efficacy of SSRIs for OCD and they are generally considered to be similar in efficacy [25]. Clomipramine generally has a higher sideeffect burden than SSRIs. Therefore, an SSRI is recommended as first-line pharmacological treatment [26]. When choosing an SSRI, consider potential drug-drug interactions, comorbid medical conditions, individual side-effect profiles, patient age, prior treatment response, and family history of treatment response [26]. A true trial of an SSRI in OCD includes at least a moderate dose for at least 12 weeks. Please see Table 1, adapted from [26], for details. We have eliminated citalopram from the table because of increasing concern about corrected QT (QTc) prolongation with this agent, especially at higher doses (see [27] for details). Although escitalopram is not FDAapproved for the treatment of OCD in the US, it has an indication for the treatment of OCD in Europe and has been shown to improve levels of disability and workrelated functioning [28]. Please be mindful that children who have been prescribed SSRIs should be monitored closely for possible changes in suicidal ideation [29].

\section{Clomipramine}

Clomipramine is a tricyclic antidepressant with the active metabolite desmethylclomipramine. It is more anticholinergic and sedating than SSRIs. It also tends to cause more weight gain. The potential for cardiac toxicity exists and regular electrocardiograms (EKGs) are useful in monitoring heart rate, rhythm, and QTc interval. Blood levels of clomipramine and desmethylclomipramine must also be monitored. However, for those who do not respond to one or more SSRI trials (defined by a less than $25 \%$ reduction in overall Y-BOCS score [22]), clomipramine is a good option, as a meta-analysis has suggested that it is more effective than the SSRIs [30]. Clomipramine is serotoninspecific and desmethylclomipramine is norepinephrinespecific; the drug is converted to desmethylclomipramine by CYP1A2. Fluvoxamine inhibits CYP1A2. Therefore, some clinicians attempt to raise the clomipramine/ desmethylclomipramine ratio by adding $25 \mathrm{mg}$ of fluvoxamine to existing clomipramine treatment. This strategy is employed in order to increase the serotonin reuptake inhibition of clomipramine. When clomipramine is combined with any SSRI, regular monitoring of blood levels and EKGs is recommended in order to avoid cardiac and central nervous system toxicity [31]. Levels that have been recommended for effective treatment [31] include 225 to $350 \mathrm{ng} / \mathrm{mL}$ for clomipramine and combined clomipramine and desmethylclomipramine levels of less than or equal to $500 \mathrm{ng} / \mathrm{mL}$. Please note that individuals with low CYP1A2 metabolic activity require lower doses of clomipramine.

\section{Augmentation of Serotonin Reuptake Inhibitors with Antipsychotics}

If an individual does not respond to initial SSRI treatment ( $<25 \%$ reduction in Y-BOCS score) or exhibits a partial response, he or she may benefit from augmentation of the SSRI with an antipsychotic medication [32]. The antipsychotic drugs that have evidence for their use include

Table I. Adult selective serotonin reuptake inhibitor dosing guidelines for obsessive-compulsive disorder

\begin{tabular}{lcccc}
\hline $\begin{array}{l}\text { Serotonin reuptake } \\
\text { inhibitor }\end{array}$ & Starting $^{\mathbf{a}}$ & Usual target & Usual maximum & Occasional $^{\mathbf{b}}$ \\
\hline Clomipramine & 25 & $100-250$ & 250 & $\mathrm{c}$ \\
Escitalopram & 10 & 20 & 40 & 60 \\
Fluoxetine & 20 & $40-60$ & 80 & 120 \\
Fluvoxamine & 50 & 200 & 300 & 450 \\
Paroxetine & 20 & $40-60$ & 60 & 100 \\
Sertraline $^{d}$ & 50 & 200 & 200 & 400 \\
\hline
\end{tabular}

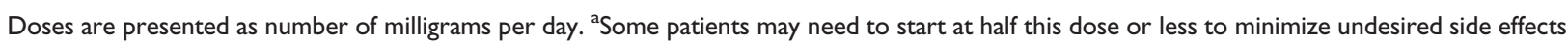

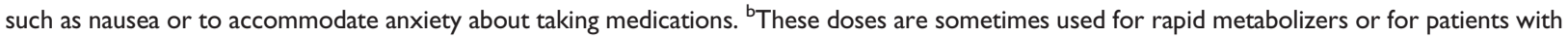
no or mild side effects and inadequate therapeutic response after 8 weeks or more at the usual maximum dose. ${ }^{\mathrm{C}} \mathrm{Combined}$ plasma levels of clomipramine plus desmethylclomipramine 12 hours after the dose should be kept below $500 \mathrm{ng} / \mathrm{mL}$ to $\mathrm{minimize}$ risk of seizures and cardiac conduction delay. 'Sertraline, alone among the selective serotonin reuptake inhibitors, is better absorbed with food. 
haloperidol, risperidone, and aripiprazole; less evidence exists for the use of quetiapine or olanzapine [33-41]. Please consult our more detailed treatment manual [25] for details on dosing strategies for antipsychotic augmentation. Determining the best time during course of treatment to begin antipsychotic augmentation has often been questioned, given that a true SRI trial in OCD is at least a moderate dose for a full 12 weeks. A meta-analysis [40] suggests that when compared to initiating antipsychotic augmentation before 12 weeks of SRI treatment, over 25\% more patients will respond with a longer duration of the initial SRI treatment. In addition, this meta-analysis provided evidence that $\mathrm{OCD}$ with comorbid tics responds particularly well to antipsychotic augmentation of SRIs. Moreover, a recent study [42] compared the effects of augmenting SRIs with ERP (17 sessions twice weekly) versus risperidone (up to $4 \mathrm{mg} /$ day) or placebo. Patients receiving ERP had significantly greater reductions in week-8 Y-BOCS scores compared to those receiving either risperidone or placebo, and more patients receiving ERP responded as defined by a mean Y-BOCS score decrease of greater than or equal to $25 \%$ ( $80 \%$ responded in the ERP group, $23 \%$ in the risperidone group, and $15 \%$ in the placebo group). Interestingly, reductions in Y-BOCS scores for those receiving risperidone augmentation did not differ significantly from reductions exhibited by those receiving placebo.

\section{Augmentation of Serotonin Reuptake Inhibitors with Other Agents}

A different augmentation strategy that targets the serotonin system includes augmenting SRIs with $5-\mathrm{HT}_{3}$ antagonists. Preliminary evidence exists for ondansetron and granisetron [43-45]. In fact, an additional recent study of ondansetron augmentation of SRIs found that $12 / 21(57 \%)$ of patients responded to ondansetron augmentation initiated at $0.25 \mathrm{mg}$ twice a day for 2 weeks, titrated to $0.5 \mathrm{mg}$ twice a day for an additional 10 weeks [46]. After discontinuation of ondansetron, Y-BOCS scores increased (worsened) by an average of $15.5 \%$ in the whole sample of participants and by $38.3 \%$ in the sample of participants who responded to the initial augmentation. In addition, there has been interest in augmenting SRIs with memantine [47], lamotrigine [48], opiramate [49,50], d-amphetamine, and caffeine [51].

\section{Radio/Neurosurgical Procedures}

For cases that are documented to be extremely severe, not responding to multiple therapeutic interventions, gamma knife radiosurgery and deep brain stimulation have been used. Gamma knife radiosurgery was used in OCD prior to deep brain stimulation. It is not FDA-approved and consists of anterior capsulotomy, limbic leucotomy, and cingulotomy [26]. Deep brain stimulation is now also an option as it has received a "Humanitarian Device Exemption" from the FDA for severe, intractable OCD. To date, a relatively small number of patients have had the procedure, and the targets and programming paradigms are not standardized. Some targets include the nucleus accumbens, ventral internal capsule, and ventral striatum [52].

\section{Transcranial Magnetic Stimulation}

The data on transcranial magnetic stimulation (TMS) for OCD are mixed. In addition to questions about efficacy, there are questions about what sites should be targeted. Some studies suggest that targeting the pre-supplementary motor area with low-frequency $(1 \mathrm{~Hz})$ TMS can be useful $[53,54]$. In addition, targeting the anterior cingulate cortex with high-frequency $(20 \mathrm{~Hz})$ stimulation with deep TMS [55] may be effective in resistant OCD, but further controlled studies are required to establish the efficacy of this approach.

\section{Conclusions}

OCD is an often debilitating condition that is treatable. Unfortunately, many patients hide their symptoms due to shame, and much misdiagnosis and provision of ineffective treatment exists. Patients often suffer either in silence or in ineffective treatment for many years. Even with appropriate treatment, symptoms can wax and wane. Initiation and continuation of appropriate treatment, the mainstays of which are ERP and SRIs, is crucial. ERP is recommended as first-line treatment for mild to moderate symptoms as measured by the Y-BOCS. For more severe symptoms or when ERP is not available, an SRI is recommended as first-line treatment as SRIs are better tolerated than clomipramine, although clomipramine appears to be more effective than the SRIs. Several pharmacological augmentation strategies exist, and radio/ neurosurgical procedures are reserved for documented severe, treatment-refractory cases. We highly recommend that clinicians and patients visit the International OCD Foundation's website when searching for treatment providers or support groups (www.ocfoundation.org).

\section{Abbreviations}

EKG, electrocardiogram; ERP, exposure and response prevention; DSM-V, Diagnostic and Statistical Manual of Mental Disorders-Fifth Edition; FDA, US Food and Drug Administration; OCD, obsessive-compulsive disorder; SRI, serotonin reuptake inhibitor; SSRI, selective serotonin reuptake inhibitor; TMS, transcranial magnetic stimulation; Y-BOCS, Yale-Brown Obsessive-Compulsive Scale.

\section{Disclosures}

Phillip J. Seibell has received honoraria from the British Medical Journal Group. Eric Hollander has received 
research grants from Transcept (Pt. Richmond, CA, USA), Brainsway (Jerusalem, Israel), Roche (Basel, Switzerland), Forest (New York, NY, USA), and Sunovion.

\section{References}

I. American Psychiatric Association: Diagnostic and statistical manual of mental disorders. 5th Edition. Arlington: American Psychiatric Publishing; 2013.

2. Frost RO: Treatment of Hoarding. Expert Rev Neurther 2010, 10:25I-6I.

3. Kessler RC, Chiu WT, Demler O, Merikangas KR, Walters EE: Prevalence, severity, and comorbidity of I2-month DSM-IV disorders in the National Comorbidity Survey Replication. Arch Gen Psychiatry 2005, 62:617-27.

\section{FlOOOPrime}

\section{RECOMMENDED}

4. Ruscio AM, Stein DJ, Chiu WT, Kessler RC: The epidemiology of obsessive-compulsive disorder in the National Comorbidity Survey Replication. Mol Psychiatry 2010, 15:53-63.

\section{FIOOOPrime}

\section{RECOMMENDED}

5. Weissman MM, Bland RC, Canino GJ, Greenwald S, Hwu HG, Lee CK, Newman SC, Oakley-Browne, Rubio-Stipec M, Wickramaratne PJ: The cross national epidemiology of obsessive compulsive disorder. J Clin Psychiatry 1994, 55:5-10.

6. Ravizza L, Maina G, Bogetto F: Episodic and chronic obsessivecompulsive disorder. Depress Anxiety 1997, 6:154-8.

7. Skoog G, Skoog I: A 40-year follow-up of patients with obsessivecompulsive disorder. Arch Gen Psychiatry 1999, 56:121-7.

8. Grados MA, Walkup J, Walford S: Genetics of obsessivecompulsive disorders: new findings and challenges. Brain Dev 2003, 25:55-6I.

9. Nicolini H, Hanna GL, Baxter L, Schwartz J, Weissbecker K, Spence MA: Segregation analysis of obsessive compulsive and associated disorders: preliminary results. Ursus Medicus 1991, 1:25-8.

10. Cavallini MC, Pasquale L, Bellodi L, Smeraldi E: Complex segregation analysis for obsessive compulsive disorder and related disorders. Am J Med Genet 1999, 88:38-43.

II. Cavallini MC, Bertelli S, Chiapparino D, Riboldi S, Bellodi L: Complex segregation analysis of obsessive-compulsive disorder in 141 families of eating disorder probands, with and without obsessive-compulsive disorder. Am J Med Genet 2000, 96:384-91.

12. Nestadt G, Lan T, Samuels J, Riddle M, Bienvenu OJ 3rd, Liang KY, Hoehn-Saric R, Cullen B, Grados M, Beaty TH, Shugart YY: Complex segregation analysis provides compelling evidence for a major gene underlying obsessive-compulsive disorder and for heterogeneity by sex. Am J Hum Genet 2000, 67:1611-6.

13. Neziroglu F, Anemone R, Yaryura-Tobias JA: Onset of obsessive-compulsive disorder in pregnancy. Am J Psychiatry 1992, 149:947-50.

\section{FlOOOPrime}

RECOMMENDED

14. World Health OrganizationThe World Health Report 200IMental Health: New Understanding, New Hope. Geneva, Switzerland: WHO; 2001.

15. Pallanti S, Quercioli L: Treatment-refractory obsessive-compulsive disorder: methodological issues, operational definitions and therapeutic lines. Prog Neuropharmacological Biol Psychiatry 2006, 30:400-12.

16. Bjorgvinsson T, Hart J, Heffelfinger S: Obsessive-compulsive disorder: update on assessment and treatment. J Psychiatr Pract 2007, 13:362-72.

17. Brem S, Hauser TU, lannaccone R, Brandeis D, Drechsler R, Walitza S: Neuroimaging of cognitive brain function in pediatric obsessive compulsive disorder: a review of literature and preliminary meta-analysis. J Neural Transm 2012, I I 9: I425-48.

\section{FIOOOPrime}

18. Perani D, Colombo C, Bressi S, Bonfanti A, Grassi F, Scarone S, Bellodi L, Smeraldi E, Fazio F: (18F)FDG PET study in obsessivecompulsive disorder. A clinical/metabolic correlation study after treatment. Br J Psychiatry 1995, 166:244-50.

\section{FlOOOPrime \\ RECOMMENDED}

19. Schwartz JM, Stoessel PW, Baxter LR Jr, Martin KM, Phelps ME: Systematic changes in cerebral glucose metabolic rate after successful behavior modification treatment of obsessivecompulsive disorder. Arch Gen Psychiatry 1996, 53:109-13.

\section{FIOOOPrime}

20. Snider LA, Swedo SE: PANDAS: current status and directions for research. Mol Psychiatry 2004, 9:900-7.

21. Steketee G, Frost R, Bogart K: The Yale-Brown Obsessive Compulsive Scale: interview versus self-report. Behav Res Ther 1996, 34:675-84

22. Seibell PJ, Pallanti S, Hughes ME, Bernardi S, Hollander E: ObsessiveCompulsive Disorder. 5th Edition. BMJ Best Practice/Point of Care; 2013.

23. Foa EB, Liebowitz MR, Kozak MJ: Randomized, Placebo-Controlled Trial of Exposure and Ritual Prevention, Clomipramine, and Their Combination in the Treatment of Obsessive-Compulsive Disorder. Am J Psychiatry 2005, 162:151-61.

\section{FlOOOPrime
RECOMMENDED}

24. Olatunji BO, Davis ML, Powers MB, Smits JA: Cognitive-behavioral therapy for obsessive-compulsive disorder: a meta-analysis of treatment outcome and moderators. J Psychiatr Res 2013, 47:33-4I.

\section{FIOOOPrime}

25. Soomro GM, Altman D, Rajagopal S, Oakley-Browne M: Selective serotonin re-uptake inhibitors (SSRIs) versus placebo for obsessive compulsive disorder. Cochrane Database Syst Rev 2008, I:CD00I765.

\section{FlOOOPrime}

RECOMMENDED

26. American Psychiatric Association: Practice guideline for the treatment of patients with obsessive-compulsive disorder. Am J Psychiatry 2007, 164:1-56.

27. Koran LM, Simpson HB: Guideline Watch (March 2013): Practice guideline for the treatment of obsessive-compulsive disorder. Arlington: American Psychiatric Association; 2013.

28. Hollander E, Stein DJ, Fineberg NA, Marteau F, Legault M: Quality of life outcomes in patients with obsessive-compulsive disorder: relationship to treatment response and symptom relapse. J Clin Psychiatry 2010, $71: 784-92$.

29. Bridge JA, lyengar S, Salary CB, Barbe RP, Birmaher B, Pincus HA, Ren L, Brent DA: Clinical response and risk for reported suicidal ideation and suicide attempts in pediatric antidepressant treatment: a meta-analysis of randomized controlled trials. JAMA 2007, 297:1683-96.

\section{FlOOOPrime}

\section{RECOMMENDED}

30. Ackerman DL, Greenland S: Multivariate meta-analysis of controlled drug studies for obsessive-compulsive disorder. J Clin Psychopharmacol 2002, 22:309-17.

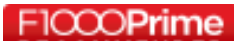

\section{RECOMMENDED}

3I. Stanford OCD Program: Pharmacological Treatments. [http://ocd.stanford.edu/treatment/pharma.html on 2/27//4] 
32. Ipser JC, Carey P, Dhansay $Y$, Fakier N, Seedat S, Stein DJ: Pharmacotherapy augmentation strategies in treatmentresistant anxiety disorders. Cochrane Database Syst Rev 2006, 4:CD005473.

\section{FlOOOPRime
RECOMMENDED}

33. McDougle CJ, Epperson CN, Pelton GH, Wasylink S, Price LH: A doubleblind, placebo-controlled study of risperidone addition in serotonin reuptake inhibitor-refractory obsessive-compulsive disorder. Arch Gen Psychiatry 2000, 57:794-801.

\section{FlOOOPrime}

\section{RECOMMENDED}

34. McDougle CJ, Fleischmann RL, Epperson CN, Wasylink S, Leckman JF, Price LH: Risperidone addition in fluvoxamine-refractory obsessive-compulsive disorder: three cases. J Clin Psychiatry 1995, 56:526-8.

35. Hollander E, Baldini Rossi N, Sood E, Pallanti S: Risperidone augmentation in treatment-resistant obsessive-compulsive disorder: a double-blind, placebo-controlled study. Int J Neuropsychopharmacol 2003, 6:397-40I.

36. Pfanner C, Marazziti D, Dell'Osso L, Presta S, Gemignani A, Milanfranchi A, Cassano GB: Risperidone augmentation in refractory obsessive-compulsive disorder: an open-label study. Int Clin Psychopharmacol 2000, 15:297-301.

\section{FlOOOPrime} RECOMMENDED

37. Li X, May RS, Tolbert LC, Jackson WT, Flournoy JM, Baxter LR: Risperidone and haloperidol augmentation of serotonin reuptake inhibitors in refractory obsessive-compulsive disorder: a crossover study. J Clin Psychiatry 2005, 66:736-43.

\section{FlOOOPrime RECOMMENDED}

38. Komossa K, Depping AM, Meyer M, Kissling W, Leucht S: Secondgeneration antipsychotics for obsessive compulsive disorder. Cochrane Database Syst Rev 2010.

\section{FlOOOPrime}

39. Muscatello MR, Bruno A, Pandolfo G, Micò U, Scimeca G, Romeo VM, Santoro V, Settineri S, Spina E, Zoccali RA: Effect of aripiprazole augmentation of serotonin reuptake inhibitors or clomipramine in treatment-resistant obsessive-compulsive disorder: a double-blind, placebo-controlled study. J Clin Psychopharmacol 201I, 31:174-9.

\section{FlOOOPrime}

40. Bloch $\mathrm{MH}$, Landeros-Weisenberger A, Kelmendi B, Coric V, Bracken MB, Leckman JF: A systematic review: antipsychotic augmentation with treatment refractory obsessive-compulsive disorder. Mol Psychiatry 2006, I I:622-32.

\section{FlOOOPrime \\ RECOMMENDED}

41. Fineberg NA, Stein DJ, Premkumar P, Carey P, Sivakumaran T, Vythilingum B, Seedat S, Westenberg $H$, Denys D: Adjunctive quetiapine for serotonin reuptake inhibitor-resistant obsessivecompulsive disorder: a meta-analysis of randomized controlled treatment trials. Int Clin Psychopharmacol 2006, 21:337-43.

42. Simpson HB, Foa EB, Liebowitz MR, Huppert JD, Cahill S, Maher MJ, McLean CP, Bender J Jr, Marcus SM, Williams MT, Weaver J, Vermes D, Van Meter PE, Rodriguez Cl, Powers M, Pinto A, Imms P, Hahn CG, Campeas R: Cognitive-behavioral therapy vs risperidone for augmenting serotonin reuptake inhibitors in obsessive-compulsive disorder: a randomized clinical trial. JAMA Psychiatry 2013, 70:1190-9.

\section{FlOOOPrime}

43. Pallanti S, Bernardi S, Antonini S, Singh N, Hollander E: Ondansetron augmentation in treatment-resistant obsessive-compulsive disorder: a preliminary, single-blind, prospective study. CNS Drugs 2009, 23:1047-55.

44. Soltani F, Sayyah M, Feizy F, Malayeri A, Siahpoosh A, Motlagh I: A double-blind, placebo-controlled pilot study of ondansetron for patients with obsessive-compulsive disorder. Hum. Psychopharmacol 2010, 25:509-13.

\section{FIOOOPrime}

\section{RECOMMENDED}

45. Askari N, Moin M, Sanati M, Tajdini M, Hosseini SM, Modabbernia A, Najand B, Salimi S, Tabrizi M, Ashrafi M, Hajiaghaee R, Akhondzadeh S: Granisetron adjunct to fluvoxamine for moderate to severe obsessive-compulsive disorder: a randomized, double-blind, placebo-controlled trial. CNS Drugs 2012, 26:883-92.

\section{FlOOOPrime}

\section{RECOMMENDED}

46. Pallanti S, Bernardi S, Antonini S, Singh N, Hollander E: Ondansetron augmentation in patients with obsessive-compulsive disorder who are inadequate responders to serotonin reuptake inhibitors: Improvement with treatment and worsening following discontinuation. Eur Neuropsychopharmacol 20 I3, 24:375-80.

47. Ghaleiha A, Entezari N, Modabbernia A, Najand B, Askari N, Tabrizi M, Ashrafi M, Hajiaghaee R, Akhondzadeh S: Memantine add-on in moderate to severe obsessive-compulsive disorder: randomized double-blind placebo-controlled study. J Psychiatr Res 2013, 47: $175-80$.

48. Bruno A, Micò U, Pandolfo G, Mallamace D, Abenavoli E, Di Nardo F, D'Arrigo C, Spina E, Zoccali RA, Muscatello MR: Lamotrigine augmentation of serotonin reuptake inhibitors in treatmentresistant obsessive-compulsive disorder: a doubleblind, placebo-controlled study. J Psychopharmacol 20I2, 26:1456-62.

\section{FIOOOPrime}

\section{RECOMMENDED}

49. Mowla A, Khajeian AM, Sahraian A, Chohedri AH, Kashkoli F: Topiramate augmentation in resistant OCD: a doubleblind placebo-controlled clinical trial. CNS Spect 2010, 15:613-7.

50. Berlin HA, Koran LM, Jenike MA, Shapira NA, Chaplin W, Pallanti S, Hollander E: Double-blind, placebo-controlled trial of topiramate augmentation in treatment resistant obsessive-compulsive disorder. J Clin. Psychiatry 201I, 72:716-2I.

5I. Koran LM, Aboujaoude E, Gamel NN: Double-blind study of dextroamphetamine versus caffeine augmentation for treatment resistant obsessive-compulsive disorder. J Clin Psychiatry 2009, 70:1530-5

52. Aronson JP, Katnani HA, Eskandar EN: Neuromodulation for obsessive-compulsive disorder. Neurosurg Clin N Am 2014, 25:85-10।.

53. Pallanti S, Hollander E: Pharmacological, experimental therapeutic, and transcranial magnetic stimulation treatments for compulsivity and impulsivity. CNS Spectr 2014, 19:50-6I.

54. Mantovani A, Rossi S, Bassi BD, Simpson HB, Fallon BA, Lisanby SH: Modulation of motor cortex excitability in obsessive-compulsive disorder: an exploratory study on the relations of neurophysiology measures with clinical outcome. Psychiatry Res 2013, 210:1026-32.

55. Carmi L, Zangen A, Zohar L, et al: Deep transcranial magnetic stimulation for resistant OCD [abstract]. Presented at 8th Annual Meeting of the International College of Obsessive Compulsive Spectrum Disorders (ICOCS): 7 May 2014; New York, NY. 